\title{
A Disjoining Pressure Study of Foam Films \\ Stabilized by Mixtures of Non-Ionic and Ionic Surfactants
}

\author{
Natalie Buchavzov ${ }^{1}$, Cosima Stubenrauch ${ }^{2 *}$ \\ ${ }^{1}$ Institut für Physikalische Chemie, Universität zu Köln, Luxemburger Str. 116, \\ D-50939 Köln, Germany \\ ${ }^{2}$ University College Dublin, School of Chemical and Bioprocess Engineering, \\ Belfield, Dublin 4, Ireland
}

\section{Supporting Information Available}

In this study the cmc values for $\beta-\mathrm{C}_{12} \mathrm{G}_{2}$ : $\mathrm{C}_{12} \mathrm{TAB}$ mixtures were experimentally obtained by measuring the respective $\sigma-c$ curves. If $\alpha$ is the mole fraction of $\mathrm{C}_{12} \mathrm{TAB}$ in the solution, then the cmc of the mixture is predicted [1] to be

$$
\mathrm{cmc}_{\text {mix }}=\frac{1}{\frac{\alpha}{\mathrm{cmc}\left(\mathrm{C}_{12} \mathrm{TAB}\right)}+\frac{(1-\alpha)}{\mathrm{cmc}\left(\mathrm{C}_{12} \mathrm{G}_{2}\right)}}
$$

Eq.A1 is based on a very simple model, which assumes ideal mixing. Deviations from eq.A1 are only expected if there is a large interaction parameter associate with the system [1], which is not the case for cationic / non-ionic surfactant mixtures in general and for $\mathrm{C}_{12} \mathrm{TAB}$ (or $\left.\mathrm{C}_{12} \mathrm{TACl}\right) / \beta-\mathrm{C}_{12} \mathrm{G}_{2}$ in particular $[2,3]$. The interaction parameter for the mixture of $\mathrm{C}_{12} \mathrm{TAB}$ and $\beta-C_{12} G_{2}$ was found to decrease from -1.54 to -0.43 with increasing amount of $\beta-C_{12} G_{2}$ indicating weak surfactant interaction and almost ideal behaviour especially at high $\beta-\mathrm{C}_{12} \mathrm{G}_{2}$ content [3]. In Fig.A1 the experimental cmc values of the surfactant mixtures as well as those calculated with eq.A1 are shown. As is seen, the $\beta-\mathrm{C}_{12} \mathrm{G}_{2}+\mathrm{C}_{12} \mathrm{TAB}$ mixture can be treated as an ideal mixture which is in agreement with the results obtained by other authors (see Fig.5 in [3]). 


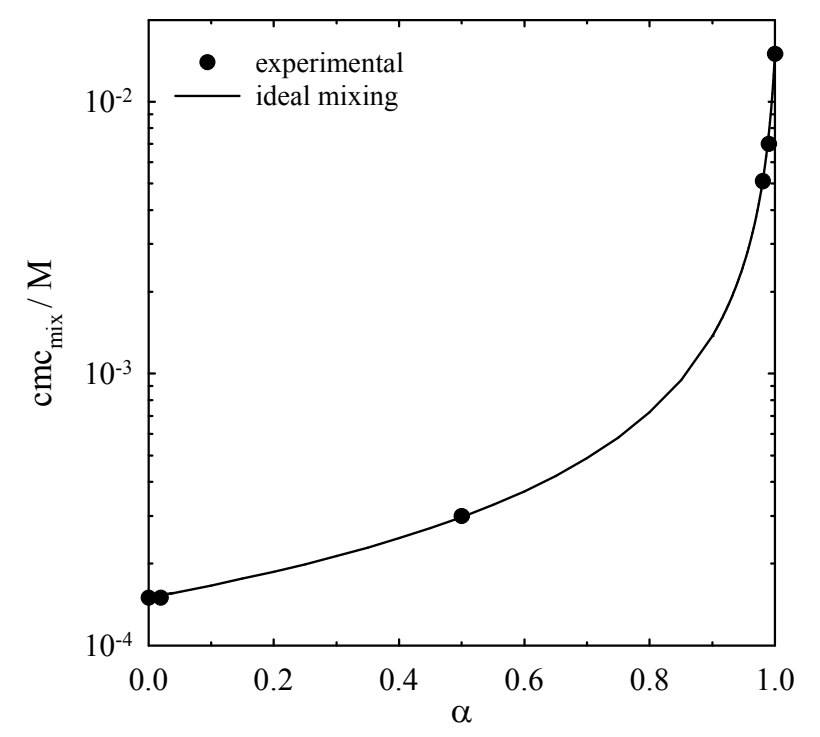

Fig.A1: Comparison of experimental cme values for the $\beta-\mathrm{C}_{12} \mathrm{G}_{2}+\mathrm{C}_{12} \mathrm{TAB}$ mixtures with those calculated by assuming ideal mixing of the components.

This information is available free of charge via the Internet at http: //pubs.acs.org.

\section{References}

[1] Rubingh, D.N. In Solution Chemistry of Surfactants; Mittal, K.L., Ed.; Plenum Press: New York, 1979; Vol.1, pp 337-354.

[2] Rosen, M.J.; Sulthana, S.B. J. Colloid Interface Sci. 2001, 239, 528.

[3] Zhang, R.; Zhang, L.; Somasundaran, P J. Colloid Interface Sci. 2004, 278, 453. 